\title{
ROCKING DAMAGE-FREE STEEL COLUMN BASE WITH FRICTION DEVICES: DEVELOPMENT OF ADVANCED 3D FINITE ELEMENT MODELS IN ABAQUS
}

\author{
Christoforos A. Dimopoulos ${ }^{*}, \mathrm{a}$, Fabio Freddi ${ }^{\mathrm{a}}$, Theodore Karavasilis ${ }^{\mathrm{b}}$ \\ ${ }^{a}$ University of Wawick, School of Engineering, United Kingdom \\ C.Dimopoulos@warwick.ac.uk,F.Freddi@warwick.ac.uk \\ bUniversity of Saouthampton, United Kingdom \\ T.Karavasilis@soton.ac.uk
}

\begin{abstract}
Column bases are critical components of a seismic-resistant steel building as they transfer gravity and lateral forces to the foundations. This paper focuses on the finite element (FE) modelling of a rocking damage-free steel column base, which uses post-tensioned high strength steel bars to achieve self-centering behavior and friction devices to provide energy dissipation capacity. Contrary to conventional steel column bases, the monotonic and cyclic moment-rotation behavior of the column base can be easily described using simple analytical equations. An advanced threedimensional FE model for the column base is developed in ABAQUS. The techniques used to overcome convergence issues in numerical simulations as well as the constitutive laws for the nonlinear behavior of materials and friction interfaces are described in detail. The FE model provides results that are in very good agreement with the results from the analytical momentrotation equations. The FE model results are also used to validate a simplified numerical model in OpenSees. Moreover, the FE model provides results that help to assess the level of stress concentration in critical areas of the column base and to evaluate a step-by-step design procedure that ensures damage-free behavior, self-centering capability, and adequate energy dissipation capacity.
\end{abstract}

Keywords: Column base, Self-centering, Seismic design, Finite element analysis

\section{INTRODUCTION}

Modern codes for seismic-resistant structures adopt the philosophy that strong earthquakes must be resisted by dissipative members while the rest non-dissipative members remain elastic and free of damage $[1,2]$. Typical dissipative members are the beams in moment resisting frames (MRFs) and the diagonal braces in the concentrically braced frames (CBFs) while the columns can be considered as non-dissipative members. The damage of structural components as well as the residual drifts can be significant and may lead to high repair costs and disruption of building use or occupation. To address these socio-economic risks, significant research has been given in the development of minimal-damage structures which can reduce both repair costs and downtime. Examples of such structures include steel frames with self-centering beam-column connections, self-centering braces, viscous damping devices and others [3, 4]. These earthquake-resilient steel frame typologies have been extensively studied during the last decade but little attention has been paid to the behavior of their column bases.

Conventional steel column bases typically consist of an exposed steel base plate supported on grout and tied to the concrete foundation using steel anchor rods. Column bases can be either full strength or partial strength $[1,5]$. In the first case a plastic hinge is expected to be developed at the bottom end of the first story columns. The specific damage in the columns is non-reparable and contributes to the overall residual drifts which is not desirable. In the case of a partial-strength column base, as field observations have shown after strong earthquakes, a number of difficult-to-repair damages in the column bases can be appeared such as concrete crushing, weld fracture, anchor rod fracture and 
base plate yielding [6]. Moreover, in this case the knowledge of the plastic rotation capacity of the column base would be needed which is difficult to predict. Also, recent investigations [7] have shown the complex hysteretic behavior of such column bases under cyclic loading. In current practice, conventional column bases can be designed as rigid or pinned. These two assumptions could be invalid since "pinned" column bases may possess significant stiffness while the "rigid" ones may be flexible under bending. Under seismic loading, modelling the column bases of a steel MRF as rigid leads to unconservative results in terms of the first story drift and collapse resistance [8]. Therefore, the current design assumption of perfectly rigid or pinned column bases may produce erroneous results and jeopardize economy, serviceability and safety. In addition, the design of semi-rigid column bases is not straightforward, as previous studies show that their rotational stiffness is strongly affected by the base plate flexibility and the magnitude and proportionality of the axial force [9].

A number of alternative column bases has been proposed recently with the goal of overcoming the shortcomings of conventional column bases. Some of them used steel bars as re-centering devices [10-12], while others used replaceable bolts [13] in an effort to direct all the damage in these elements under an earthquake event. An alternative approach has been presented in $[14,15]$ where the column base was equipped with asymmetric friction devices.

This paper focuses on the finite element (FE) modelling of a rocking damage-free steel column base, which uses post-tensioned high strength steel bars to achieve self-centering behavior and friction devices to provide energy dissipation capacity. Contrary to conventional steel column bases, the monotonic and cyclic moment-rotation behavior of the column base can be easily described using simple analytical equations. A three-dimensional non-linear FE model of the column base is developed in ABAQUS [16] in order to validate the accuracy of the momentrotation analytical equations and assess the efficiency of a simplified model in OpenSees. More details on the design and the influence of the rocking column base on the seismic response of selfcentering moment resisting steel frames (SC-MRFs) under earthquake ground motions are presented in Freddi et. al [17].

\section{ROCKING DAMAGE FREE COLUMN BASE}

\subsection{Structural Details}

Fig. 1 shows the proposed rocking damage-free column base, which in concept has similarities with the column base proposed by Kamperidis et al. [18]. The column base is composed by a circular hollow section with an anchor plate welded on the top of it and a thick steel plate with rounded edges welded at its bottom. Four high strength steel bars (or strands) are symmetrically placed around the center of the column and anchored at the anchor plate with adjustable PT force to control the rocking behavior of the column base. Friction devices (FDs) are placed on both sides of the column base for energy dissipation. Friction devices are composed by two external plates bolted at the ground and an internal plate welded to the column base. Two brass sheets are used as friction material between internal and external plates (See Fig. 2(a)).

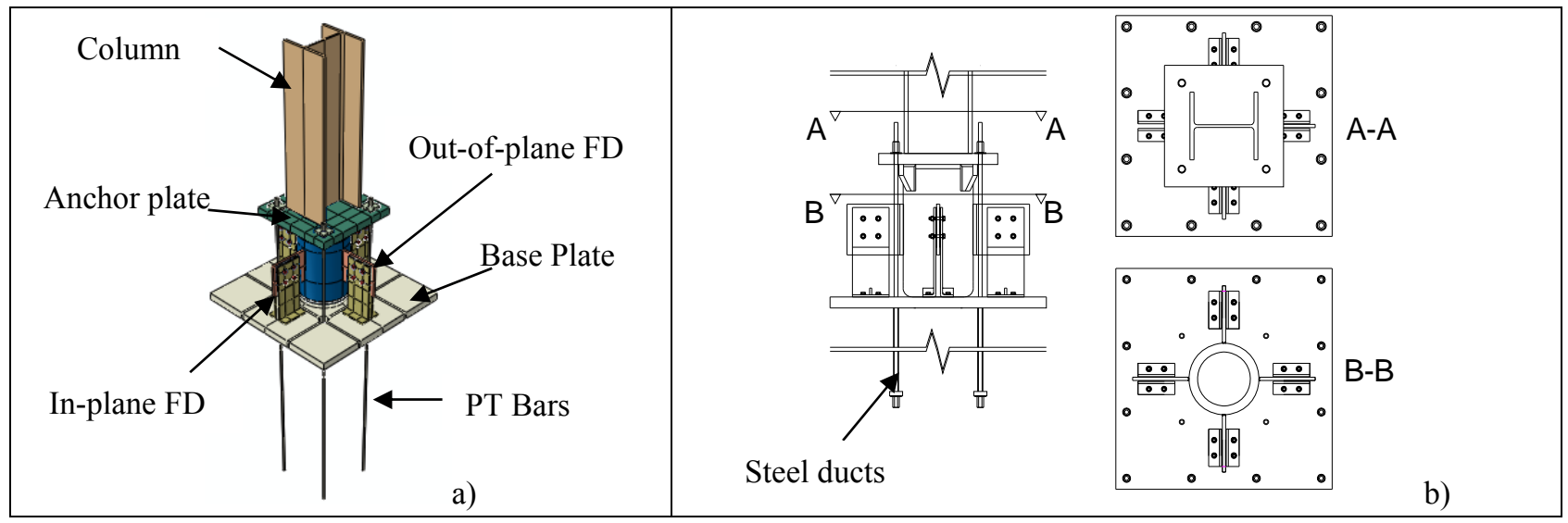

Fig. 1. Proposed column base (a) 3D view and; (b) lateral view and sections

(C) Ernst \& Sohn Verlag für Architektur und technische Wissenschaften GmbH \& Co. KG, Berlin · CE/papers (2017) 
A shear key is bolted to the column base to provide extra shear resistance to the column (see Fig. $2(b))$.

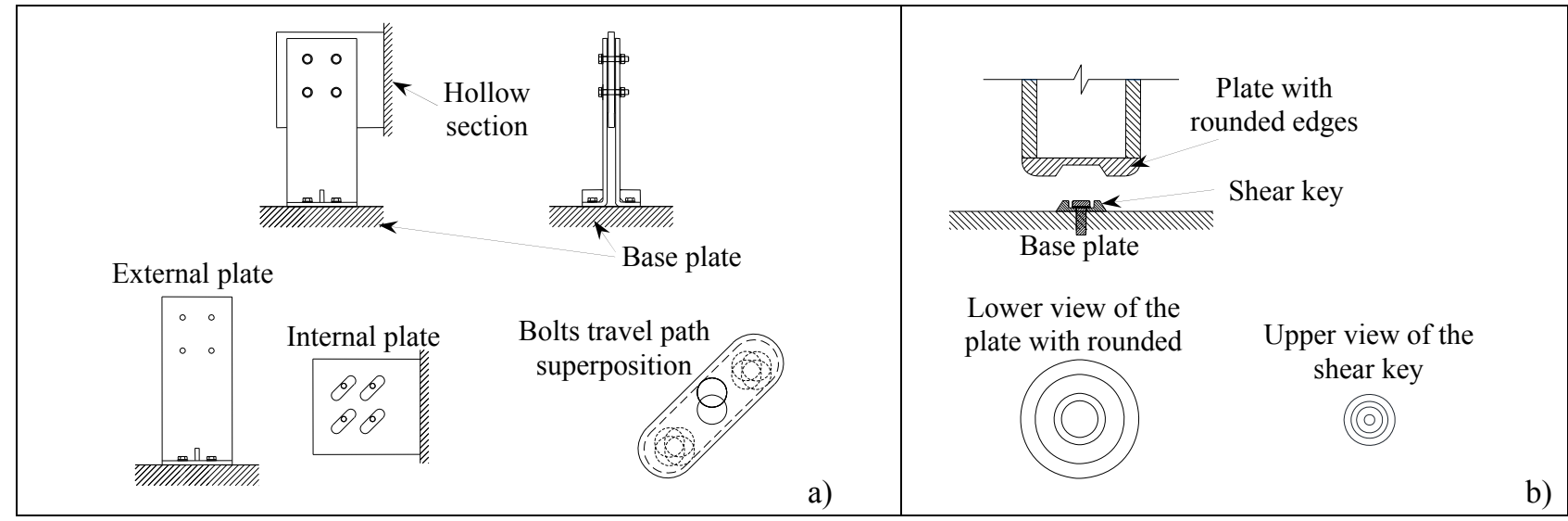

Fig. 2. (a) Details of the friction device; (b) steel plate with rounded edges and shear key.

\subsection{Nonlinear moment - rotation behaviour of the column base}

Fig. 3(a) shows the fundamental dimensions of the column base that control the moment-rotation behavior in the rocking direction, i.e. $\mathrm{b}$ is the dimension of the contact surface; bPt is the distance among the PT bars; bFD is the distance among the centers of the FDs; and hFD is the distance of the centers of the FDs from the base plate. Fig. 3(b) shows the column base at the onset of rocking with respect to its right edge under the effect of the internal axial force $(\mathrm{N})$, shear force $(\mathrm{V})$, and bending moment (M). In Fig. 3(b), F FT,u and FPT,d are the forces in the PT bars, while $F_{F D, u}, F_{F D, d}$ and $F_{F D, c}$ are the forces in the FDs. The subscripts $u$ and $d$ denote whether the point of application of these forces will move upwards or downwards during rocking. The subscript $\mathrm{c}$ denotes the force in each of the two central FDs. The lever arms of the forces in the PT bars with respect to the center of rotation are given by:

$z_{P T, u}=\left(b_{P T}+b\right) / 2 \quad z_{P T, d}=\left(b_{P T}-b\right) / 2$

while the lever arms of the forces in the FDs are given by:

$z_{F D, u}=\sqrt{\left(\left(b_{F D}+b\right) / 2\right)^{2}+h_{F D}^{2}} \quad z_{F D, c}=b / 2 \quad z_{F D, d}=\sqrt{\left(\left(b_{F D}-b\right) / 2\right)^{2}+h_{F D}^{2}}$

The moment contribution of the axial force, $\mathrm{N}$, is given by:

$M_{N}=(N \cdot b) / 2$

The forces in each PT bar are function of the rotation, $\theta$, of the column base and are given by:

$F_{P T, u}=T_{P T}+K_{P T} \cdot z_{P T, u} \cdot \theta \quad$ for $\theta \leq \theta_{P T, u, y}$

$F_{P T, d}=T_{P T}-K_{P T} \cdot z_{P T, d} \cdot \theta \quad$ for $\theta \leq \theta_{P T, u, f}$

where TPT $_{\mathrm{PT}}$ is the initial post-tensioning force of each PT bar; K Ерт, АРт and LPт are respectively the Young's modulus, the cross-sectional area and the length of each PT bar; $\theta_{\mathrm{PT}, \mathrm{u}, \mathrm{y}}$ is the rotation at which the PT bars (in position $\mathrm{u}$ ) yield; and $\theta_{\mathrm{PT}, \mathrm{d}, \mathrm{f}}$ is the rotation at which the force of the PT bars (in position d) becomes zero, i.e. when loss of post-tensioning occurs. The PT bars should be designed to avoid either yielding or loss of post-tensioning for a target rotation $\theta \mathrm{T}$ by using the following inequalities:

$\theta_{P T, u, y}=\left(F_{P T, y}-T_{P T}\right) / K_{P T} \cdot z_{P T, u} \rightarrow L_{P T} \geq\left(E_{P T} \cdot A_{P T} \cdot z_{P T, u} \cdot \theta_{T}\right) /\left(F_{P T, y}-T_{P T}\right)$

$\theta_{P T, d, f}=T_{P T} /\left(K_{P T} \cdot z_{P T, d}\right) \rightarrow T_{P T} \geq K_{P T} \cdot z_{P T, d} \cdot \theta_{T}$ 
where $F_{P T, y}=f_{y, P T} \cdot A_{P T}$ is the yield force of the PT bars and $f_{y, P T}$ is the yield stress of their steel material. Therefore, the moment contribution of the PT bars is given by:

$$
M_{P T}(\theta)=2\left[T_{P T}\left(z_{P T, u}-z_{P T, d}\right)+K_{P T}\left(z_{P T, u}^{2}+z_{P T, d}^{2}\right) \theta\right] \text { for } \theta \leq \theta_{T}
$$

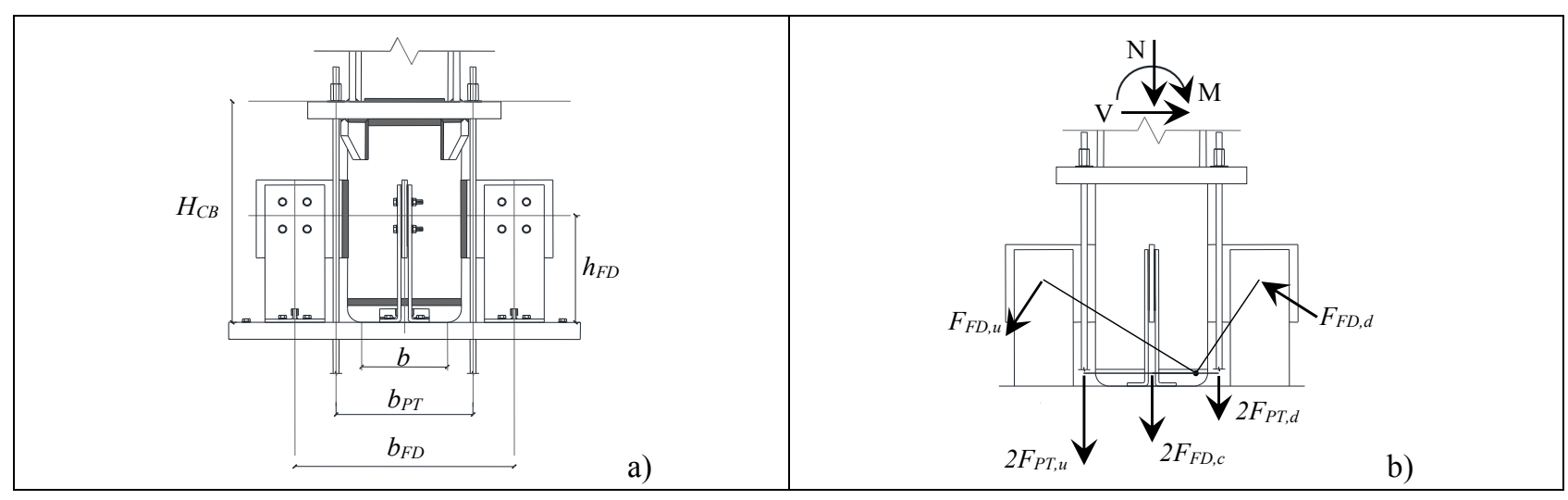

Fig. 3. Column base (a) fundamental dimensions and (b) forces in the FDs and PT bars at the onset of rocking for loading from left to right.

The friction force, $\mathrm{F}_{\mathrm{FD}, \mathrm{i}}$, in each $\mathrm{FD}$ is given by:

$F_{F D, i}=\mu_{F D} \cdot n_{b} \cdot N_{b}$ with $i=u, c, d$

where $\mu \mathrm{FD}$ is the friction coefficient of the surfaces in contact; $\mathrm{n}_{\mathrm{b}}$ is the number of bolts and $\mathrm{Nb}_{\mathrm{b}}$ is the bolt preloading force.

Therefore, the moment contribution of the FDs is given by:

$M_{F D}=2 F_{F D}\left(z_{F D, u}+2 z_{F D, c}+z_{F D, d}\right)$

Fig. 4(a) shows the moment contributions of the axial force, $\mathrm{M}_{\mathrm{N}}$; the PT bars, MPT; and the FDs, $\mathrm{M}_{\mathrm{FD}}$. The decompression moment, $\mathrm{M}_{\mathrm{E}}$, and the moment at the onset of rocking, $\mathrm{M}_{\mathrm{D}}$, are given by:

$M_{E}=M_{N}+M_{P T, 0} ; \quad M_{D}=M_{E}+M_{F D}$

where MPT, 0 is the moment provided by the PT bars at zero rotation (i.e. $\theta=0.0$ in $E q$. (6)).

The rotational stiffness contribution of the PT bars is given by:

$S_{P T}=2 K_{P T}\left(z_{P T, u}^{2}+z_{P T, d}^{2}\right)$

and therefore, the moments corresponding to points 1 to 4 of the cyclic M- $\theta$ behavior of the column base in Fig. 4(b) are given by:

$M_{1}=M_{D}=M_{N}+M_{P T, 0}+M_{F D} ; M_{2}=M_{D}+S_{P T} \theta_{2} ; M_{3}=M_{D}+S_{P T} \theta_{2}-2 M_{F D} ; M_{4}=M_{D}-2 M_{F D}$

To ensure that the column base provides full self-centering capability, the following relation should be satisfied:

$M_{4} \geq 0 \rightarrow M_{E} \geq M_{F D}$

The aforementioned equations do not account for geometrical nonlinearities (i.e. P- $\Delta$ effects), material nonlinearities (i.e. PT bar yielding), and mechanical nonlinearities (i.e. loss of posttensioning in the PT bars).

Geometric nonlinearities (P- $\Delta$ effects) reduce the rotational stiffness of the column base. The moment contribution of the axial force is calculated by:

$M_{N}^{P \Delta}=N \cdot\left(b / 2-H_{C} \cdot \theta\right)$

where $\mathrm{Hc}_{\mathrm{c}}$ is the height of the column. Moreover, the level arms of the PT bar forces are given by: 


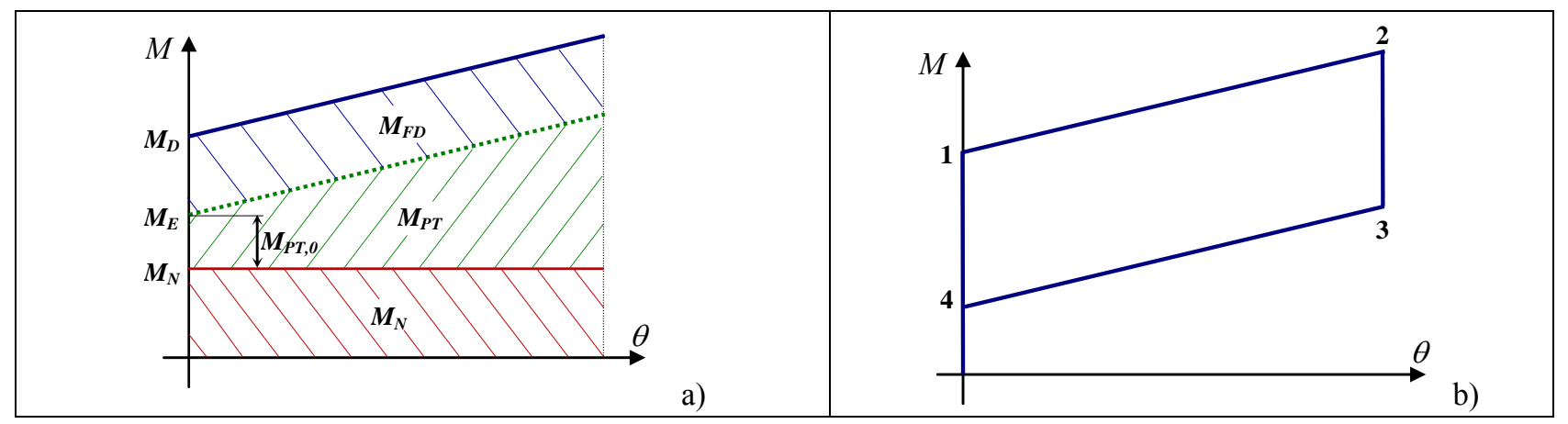

Fig. 4. Moment-rotation behavior of the column base. (a) Moment contribution of the axial force, $M_{N}$; of the PT bars, $M_{P T}$; and of the FDs, $M_{F D}$; (b) hysteretic behavior.

$z_{P T, u}^{P A}=z_{P T, u}-H_{C B} \theta \quad z_{P T, d}^{P A}=z_{P T, d}+H_{C B} \theta$

where $\mathrm{H}_{\mathrm{CB}}$ is defined in Fig. 3(a). The change in the direction of the force of the PT bars is negligible. The moment contribution of the PT bars is given by:

$M_{P T}^{P \perp}(\theta)=M_{P T, 0}+S_{P T} \theta-S_{P T}^{P \perp, 1} \theta-S_{P T}^{P \perp, 2} \theta^{2} \quad$ for $\theta \leq \theta_{T}$

where the quantities that reflect the reduction in the rotational stiffness of the PT bars due to geometric nonlinearities are calculated by:

$S_{P T}^{P A, I}=4 T_{P T} H_{C B}$

$S_{P T}^{P A, 2}=2 K_{P T}\left(z_{P T, u}-z_{P T, d}\right) H_{C B}$

The rotational stiffness contribution of the PT bars in case of material nonlinearities (yielding of PT bars in position $\mathrm{u}$ ), mechanical nonlinearities (loss of post-tensioning of PT bars in position d), or combination of material and mechanical nonlinearities (yielding of PT bars in position $u$ and loss of post-tensioning of PT bars in position d) are given by the following equations:

$S_{P T, y}=2 K_{P T}\left(\beta z_{P T, u}^{2}+z_{P T, d}^{2}\right) \quad S_{P T, f}=2 K_{P T} z_{P T, u}^{2} \quad S_{P T, y f}=2 \beta K_{P T} z_{P T, u}^{2}$

The moment contribution of the PT bars can be calculated in the case that $\theta \geq \theta_{\mathrm{T}}$ and $\theta_{\mathrm{T}}=\theta_{\mathrm{PT}, \mathrm{u}, \mathrm{y}}$ as:

$M_{P T}(\theta)=M_{P T, 0}+S_{P T, y} \theta_{P T, u, y}+S_{P T, y}\left(\theta-\theta_{P T, u, y}\right) \quad$ for $\theta<\theta_{P T, d, f}$

$M_{P T}(\theta)=M_{P T, 0}+S_{P T, y} \theta_{P T, u, y}+S_{P T, y}\left(\theta_{P T, u, f}-\theta_{P T, u, y}\right)+S_{P T, y f}\left(\theta-\theta_{P T, u, f}\right) \quad$ for $\theta \geq \theta_{P T, d, f}$

In the case of material, geometric, or material and geometric nonlinearities, the stiffness reduction due to geometric nonlinearities is related to the following parameters:

$S_{P T, y}^{P A, 2}=2 K_{P T}\left(\beta z_{P T, u}-z_{P T, d}\right) H_{C B} \quad S_{P T, f}^{P A, 2}=2 K_{P T} z_{P T, u} H_{C B} \quad S_{P T, y f}^{P A, 2}=2 \beta K_{P T} z_{P T, u} H_{C B}$

where $\mathrm{S}_{\mathrm{PT}, \mathrm{y}}^{\mathrm{P}, 2}$ is the stiffness reduction after yielding of PT bars in position $\mathrm{u} ; \mathrm{S}_{\mathrm{PT}, \mathrm{f}}^{\mathrm{P} \Delta, 2}$ is the stiffness reduction after loss of post-tensioning force of PT bars in position $d$, and $S_{\mathrm{PT}, y \mathrm{ff}}^{\mathrm{P} \Delta, \mathrm{f}}$ is the stiffness reduction after yielding and loss of post-tensioning force of PT bars in positions $\mathrm{u}$ and $\mathrm{d}$, respectively. Then, the moment contribution of the PT bars when $\theta \geq \theta_{T}$ and $\theta_{T}=\theta_{P T, u, y}$ as:

$$
\begin{aligned}
& M_{P T}^{P \Delta}(\theta)=M_{P T, 0}+S_{P T} \theta_{P T, u, y}+S_{P T, y}\left(\theta-\theta_{P T, u, y}\right)-S_{P T}^{P A, l} \theta-S_{P T}^{P A, 2} \theta_{P T, u, y} \theta-S_{P T, y}^{P A, 2}\left(\theta-\theta_{P T, u, y}\right) \theta ; \text { for } \theta<\theta_{P T, d, f} \\
& M_{P T}^{P \Delta}(\theta)=M_{P T, \theta}+S_{P T} \theta_{P T, u, y}+S_{P T, y}\left(\theta_{P T, u, f}-\theta_{P T, u, y}\right)+S_{P T, y f}\left(\theta-\theta_{P T, u, f}\right) \\
& -S_{P T}^{P A, l} \theta-S_{P T}^{P A, 2} \theta_{P T, u, y} \theta-S_{P T, y}^{P A, 2}\left(\theta_{P T, u, f}-\theta_{P T, u, y}\right) \theta-S_{P T, y f}^{P A, 2}\left(\theta-\theta_{P T, u, f}\right) \theta \quad \text { for } \theta \geq \theta_{P T, d, f}
\end{aligned}
$$

Similar equations can be derived for the case of $\theta_{\mathrm{T}}=\theta_{\mathrm{PT}, \mathrm{d}, \mathrm{f}}$.

(C) Ernst \& Sohn Verlag für Architektur und technische Wissenschaften GmbH \& Co. KG, Berlin · CE/papers (2017) 


\section{NONLINEAR MODELS FOR THE COLUMN BASE}

\subsection{Geometrical properties of the column base}

On the basis of a realistic 4-storey, 3-bay by 3-bay building design case, the novel column base is designed for a HEB 300 column cross-section; axial force $\mathrm{N}_{\mathrm{Ed}, \mathrm{G}}$ of the gravity load combination $(1.35 \mathrm{G}+1.50 \mathrm{Q})$ equal to $537.8 \mathrm{kN}$; and axial force $\mathrm{N}_{\mathrm{Ed}}$ of the seismic load combination $(\mathrm{G}+0.3 \mathrm{Q}+\mathrm{E})$ equal to $565.3 \mathrm{kN}$. The plastic moment of resistance $\mathrm{M}_{\mathrm{N}, \mathrm{Rd}}$ is calculated equal to $308.9 \mathrm{kNm}$. The target rotation is assumed equal to 0.023 rads. Based on the geometry of the column cross-section, a circular hollow section with $323.9 \mathrm{~mm}$ diameter and $40 \mathrm{~mm}$ thickness is adopted. A circular steel plate with the same diameter is welded at the bottom of the hollow section. Standard mechanical processing provides this plate with rounded circular edges having a radius of $40 \mathrm{~mm}$ as well as with appropriate space to accommodate the shear key. The contact surface has a dimension $b$ equal to $243.9 \mathrm{~mm}$. The anchor plate of the PT bars in the top of the hollow steel section is square and has width and thickness equal to $550 \mathrm{~mm}$ and $50 \mathrm{~mm}$, respectively. The distance among the PT bars bPT is selected equal to $390.0 \mathrm{~mm}$. Moreover, Table 1 provides the assumed material properties (E: Young's modulus; $f_{y}$ : yield stress; $f_{u}$ : ultimate stress; and $\beta$ : strain hardening ratio), which have been selected on the basis of experimental results [21, 22]. Applying the design methodology presented in [17], PT bars with length and diameter equal to 2242 and $15 \mathrm{~mm}$ respectively are

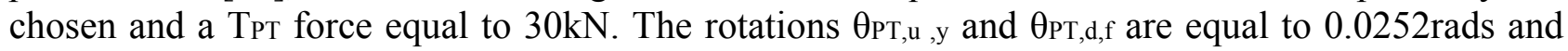
0.0255 rads, respectively.

Table 1. Material properties

\begin{tabular}{c|c|ccccc} 
Elements & & $\boldsymbol{E}$ & $\boldsymbol{f}_{\boldsymbol{y}}$ & $\boldsymbol{f u}_{\boldsymbol{u}}$ & $\boldsymbol{\beta}$ & $\boldsymbol{v}$ \\
\hline & & {$[\mathrm{GPa}]$} & {$[\mathrm{MPa}]$} & {$[\mathrm{MPa}]$} & {[]} & {[]} \\
\hline Column and plates & $\mathrm{S} 355$ & 210 & 355 & 510 & 0.00338 & 0.30 \\
PT bars & $* * *$ & 205 & 900 & 1100 & 0.01754 & 0.30 \\
Bolts & Class 10.9 & 210 & 900 & 1000 & 0.00855 & 0.30 \\
Brass & $* * *$ & 100 & $* * *$ & $* * *$ & $* * *$ & 0.35 \\
\hline
\end{tabular}

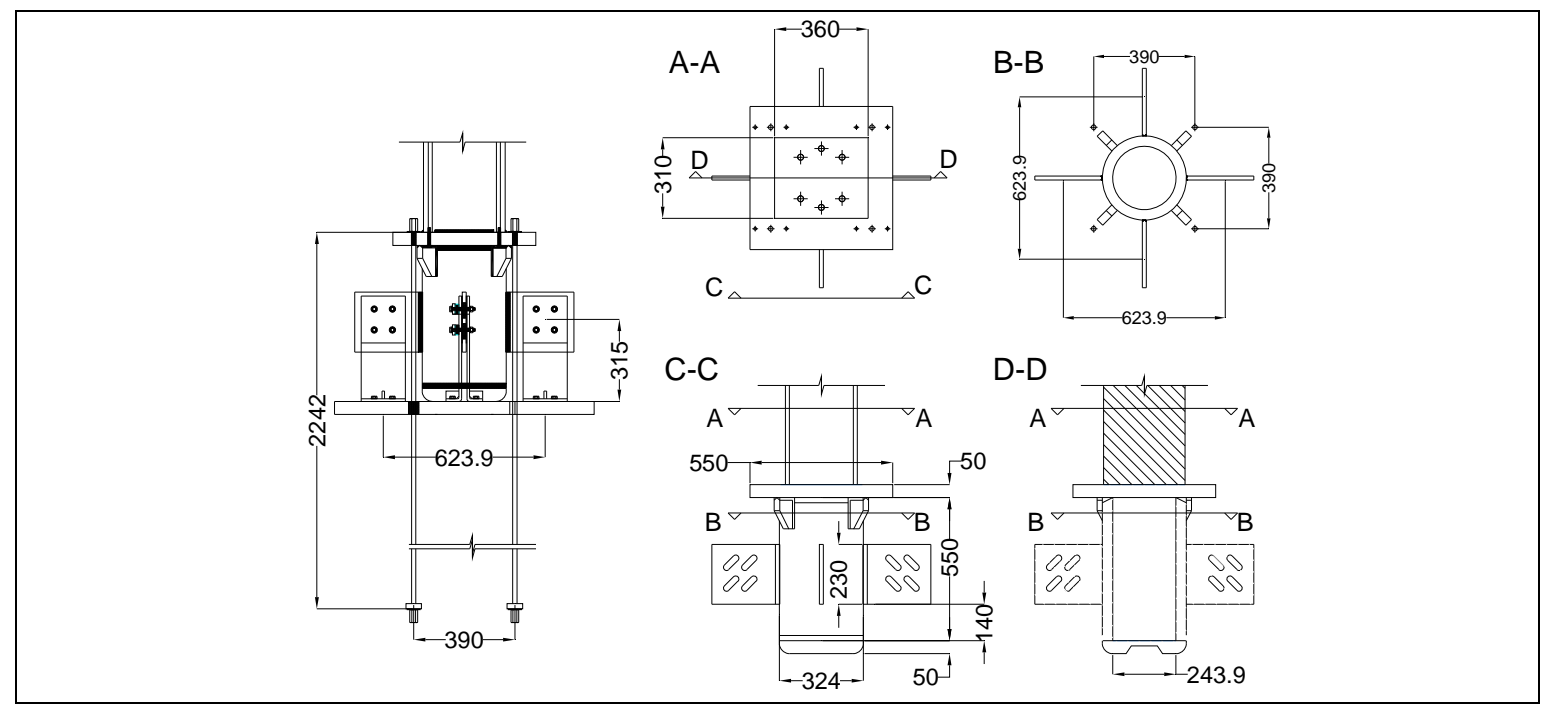

Fig. 5. Geometry of the column-base (dimensions in $\mathrm{mm}$ ).

\subsection{FE model in ABAQUS}

A detailed FE model is built in ABAQUS in order to validate the theoretical monotonic and cyclic behaviour of the column base as well as a simplified numerical OpenSees model, which is used in [17] for the seismic assessment of a SC-MRF.

For the FE discretization, the eight-node linear brick element (C3D8R) based on 'reduced integration' and 'hourglass control' is used for all components. An overview of the model and details of the mesh in areas with contact interactions are shown in Fig. 6. 
The bottom surface of the base plate and the bottom ends of the PT bars are fully fixed. Lateral and gravity loads are simulated by a controlled horizontal displacement and a concentrated vertical force applied at the centroid of the cross-section at the top of the column. A multi-point constraint is used to uniformly distribute these actions to all nodes of the top column cross-section. A 'bolt load' is used to model the initial post-tensioning force in the PT bars and the bolts. The 'apply force' option is used to keep the force in the bolts constant throughout the analysis, while the 'adjust length' option is used to allow the force in the PT bars to change due to elongation or shortening during rocking.

A TIE constraint is used to simulate welding (i.e. monolithic connection) among different parts of the column base, i.e. among the external plates of the friction devices and the base plate; the internal plates of the friction devices and the circular hollow section; the column and the anchor plate; the circular hollow section and the anchor plate; the circular hollow section and the bottom circular plate with rounded edges; and the shear key and the base plate.

Convergence of the analysis is highly influenced by the definition of adequate contact properties. Contact interaction is defined among: the base plate and the bottom column base part with the rounded edges; the PT bars, the washer, and the anchor plate; the friction interfaces and the internal plates in the friction devices. The 'surface-to-surface' interaction property is used to describe the contact behavior between the aforementioned parts. This is implemented using the HARD contact property to describe the behavior in the direction normal to the interface plane, while the PENALTY option is used for the tangential response with values of the friction coefficient equal to 0.30 for interfaces among steel parts and 0.15 for the brass-steel interfaces of the FDs.

In order to reduce as much as possible the contact difficulties during the analysis, a number of factors must be considered [16]: (i) perform an initial strain-free adjustment of nodal positions at the beginning of the analysis in order to remove initial contact openings and overclosures, (ii) restrain the rigid body motions either through ensuring that the appropriate surface pairs are initially in contact or by using ABAQUS tools ('contact controls', 'automatic stabilization') to automatically stabilize rigid bodies, (iii) choose the smaller surface as the slave surface if a smaller surface contacts a larger surface or if that distinction cannot be made, choose the master surface as the surface of the stiffer body or as the surface with the coarser mesh if the two surfaces are on structures with comparable stiffnesses.

In the simulation models an elasto-plastic material law with hardening has been taken into account using the material properties reported in Table 1. The standard 'Full Newton' solution technique is adopted together with an automatic incrementation scheme for the application of the loading.

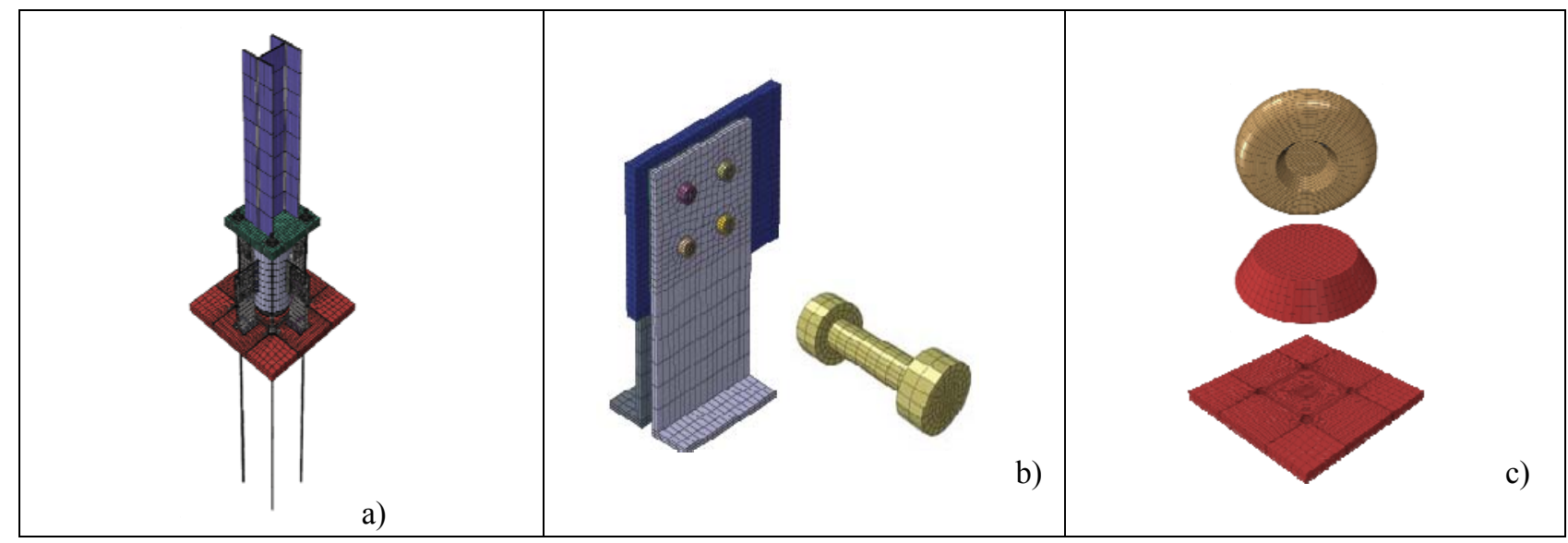

Fig. 6. (a) Overview of the FE model of the column base, (b) FE model of the plates and bolts of the friction device and (c) FE model for the plate with rounded edges, the shear key and the base plate

\subsection{Comparison of the results}

This section compares the results from the ABAQUS FE model and the analytical equations presented in Section 2.2. Results from a simplified nonlinear finite element model built in OpenSees (see description of the model in [17]) are also included for comparison purposes. The (C) Ernst \& Sohn Verlag für Architektur und technische Wissenschaften GmbH \& Co. KG, Berlin · CE/papers (2017) 
results are plotted for cases with and without P- $\Delta$ effects, i.e. with or without including large displacement effects in the analyses.

Fig. 7(a) shows the monotonic moment-rotation curve of the column base for rotations up to 0.07 rads. The results show an excellent agreement for rotations of practical interest, i.e. up to 0.03 rads. For larger rotations, the central FDs develop internal bending moments and increase the moment resisted by the column base. This is not accounted neither in the analytical equations nor in the OpenSees model and so they underestimate the response. For rotations close to 0.06rads the ABAQUS model predicts a sudden increase of the moment due to the initiation of the bearing of the bolts on the internal plates of the in-plane FDs. Both the analytical and the OpenSees model do not account for this bearing. Fig. 7(b) shows the evolution of the forces in the PT bars on the right and left sides of the column base (the loading has a direction from left to the right) as a function of the column base rotation. The analytical relations and the OpenSees model give identical results and show that both yielding and loss of post-tensioning takes place at rotations $\theta_{\mathrm{PT}, \mathrm{u}, \mathrm{y}}$ and $\theta_{\mathrm{PT}, \mathrm{d}, \mathrm{f}}$ respectively which are almost equal to the target rotation $(0.023 \mathrm{rad})$. The results from the ABAQUS model are in good agreement with the analytical equations. The only difference is that ABAQUS model shows a faster drop of the force on the right PT bars because of the deformability of the column base and the base plate due to contact or bending.

Fig. 8(a) shows the monotonic moment-rotation curve of the column base without central FDs. It can be seen that since the central FDs are absent, no additional strength is added to the column base moment resistance and the analytical predictions are in good agreement with the ABAQUS results. When the rotation exceeds $0.06 \mathrm{rad}$, bolts come into contact with the internal plates (see Fig. 8(b)), and the moment resistance exhibits a sharp increase.

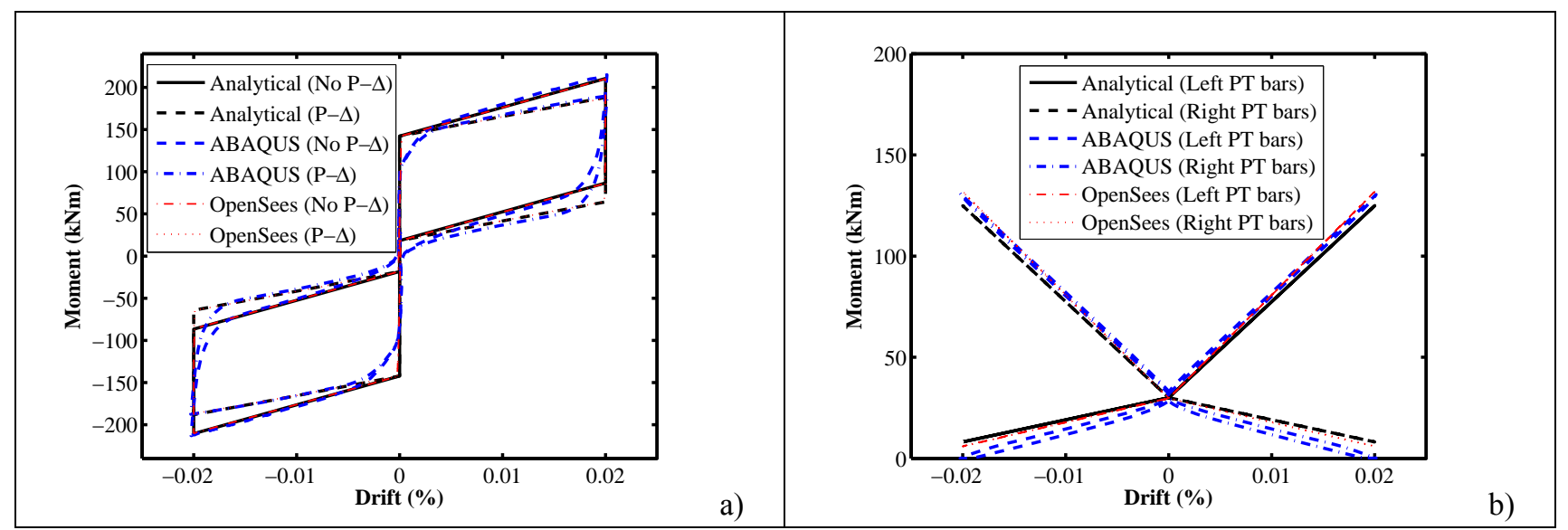

Fig. 7. (a) Monotonic moment-rotation behavior of the column base; (b) forces in the PT bars for analysis with P- $\Delta$ effects (results are practically the same for analysis without P- $\Delta$ effects)

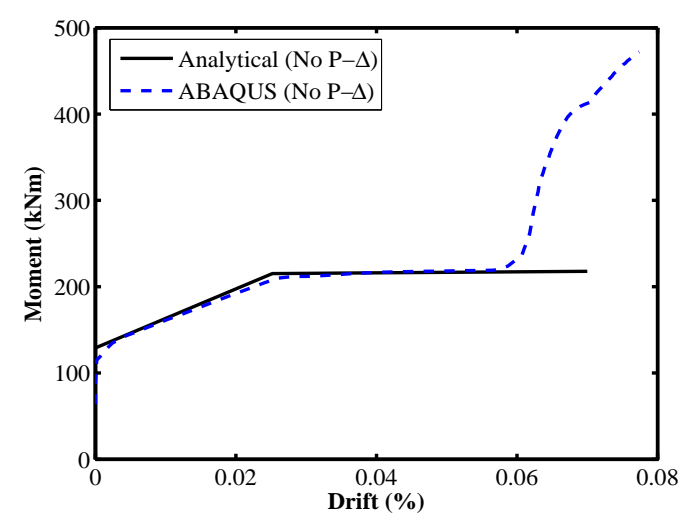

a)

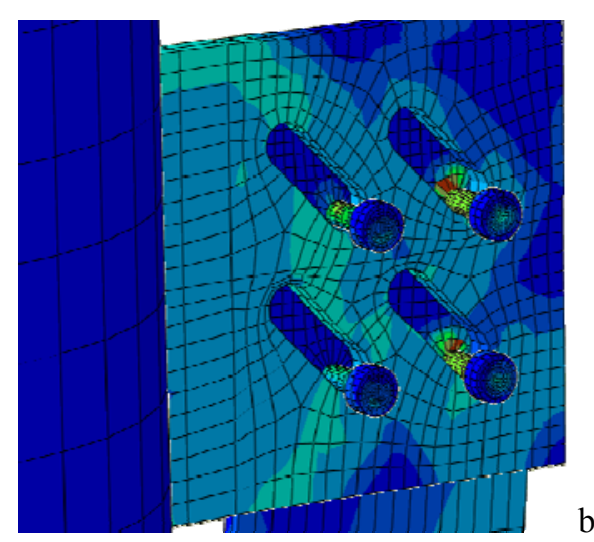

Fig. 8. (a) Monotonic moment-rotation behavior of the column base without central FDs and no P- $\Delta$ effects; (b) bearing of bolts on the internal plate of the FDs 
Fig. 9(a) shows the cyclic moment-rotation curve of the column base for rotations up to 0.02rads. All the components of the column base remain elastic (i.e. damage-free). Moreover, the results from the analytical equations and the ABAQUS model are in very good agreement. Smoother curves are obtained from ABAQUS due to modeling of the flexibility of all the column base components.

Fig. 9(b) shows the cyclic behavior of the column base for rotations up to 0.05 rads. In this case, comparison is performed only among the OpenSees and ABAQUS models since analytical equations are not derived for the cyclic behavior that involves yielding of the PT bars. Fig. 9(b) shows a very good agreement in the cyclic moment-rotation behaviors obtained from OpenSees and ABAQUS.

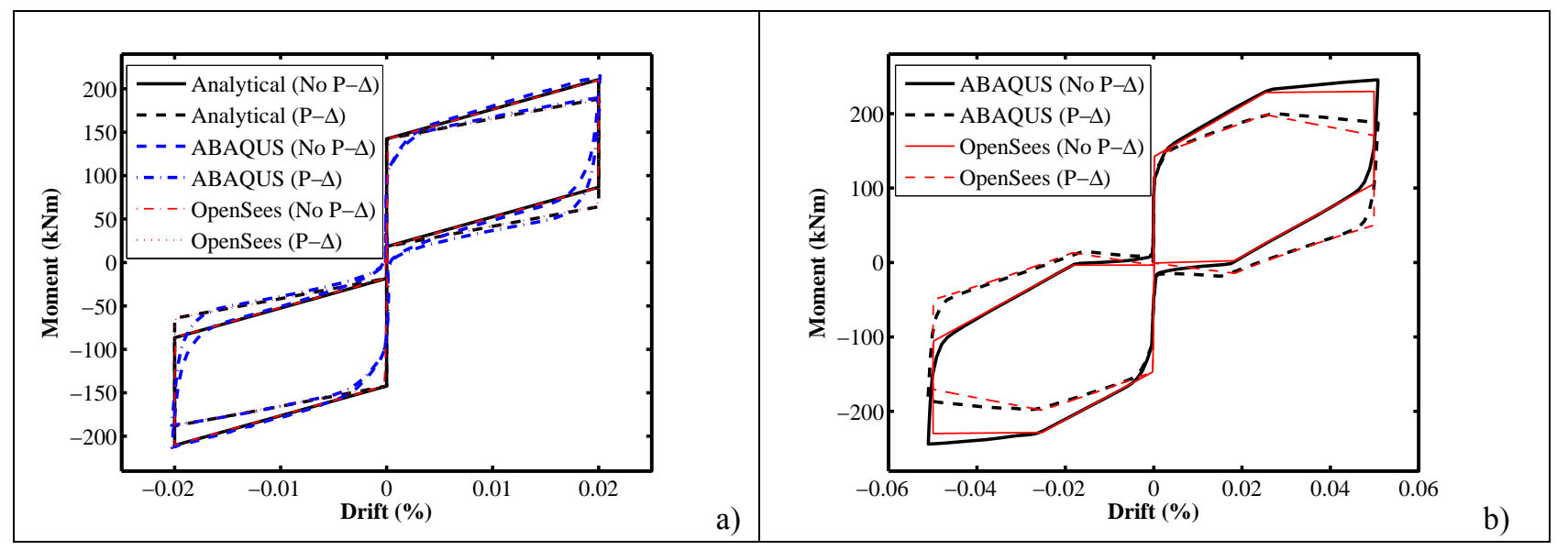

Fig. 9. (a) Cyclic moment-rotation behavior of the column base for rotations up to 0.02rads; (b) Cyclic momentrotation behavior of the column base for rotations up to 0.05 rads.

\section{SUMMARY}

The finite element modeling of a rocking damage-free steel column base has been presented. The column base uses post-tensioned (PT) high strength steel bars to control rocking behavior and friction devices to dissipate seismic energy. Contrary to conventional steel column bases, the rocking column base has monotonic and cyclic moment-rotation behaviors that are easily described using simple analytical equations. Analytical equations are provided for different cases including structural limit states that involve yielding or loss of post-tensioning in the PT bars. A threedimensional non-linear finite element (FE) model of the column base is developed in ABAQUS. The results of the FE simulations validate the accuracy of the analytical moment-rotation equations and demonstrate the efficiency of a design procedure. The results are also used to validate the accuracy of an OpenSees model, which is appropriate for seismic assessment studies of steel buildings using the rocking column base.

\section{ACKNOWLEDGEMENTS}

This research is supported by Marie Sklodowska-Curie Action Fellowships within the H2020 European Programme. Any opinions, findings, and conclusions or recommendations expressed in this paper are those of the authors and do not necessarily reflect the views of the European Commission.

\section{REFERENCES}

[1] Eurocode 8. "Design of structures for earthquake resistance. Part 1: General rules, seismic action and rules for buildings". European Committee for Standardization, Brussels, Belgium, 2005

[2] Federal Emergency Management Agency. FEMA 350. "Recommended seismic design criteria for new steel moment-frame buildings", SAC Joint Venture, Washington, DC, 2000 
[3] Christopoulos C., Filiatrault A., "Principles of passive supplemental damping and seismic isolation", IUSS Press, Pavia, Italy, 2006

[4] Chancellor N.B., Eatherton M.R., Roke D.A., Akbas T., "Self-centering seismic lateral force resisting systems: High-performance structures for the city of tomorrow", Buildings 4, pp. 520-548, 2014

[5] Eurocode 3. "Design of steel structures - Part 1.8: Design of Joints". European Committee for Standardization, Brussels, Belgium, 2005

[6] Grauvilardell J.E., Lee D., Hajjar J.F., Dexter R.J., "Synthesis of design, testing and analysis research on steel column base plate connections in high-seismic zones", Report ST-04-02, Dept. of Civil Engineering, Univ. of Minnesota, USA, 2006

[7] Rodas PT, Zareian F, Kanvinde M. "Hysteretic model for exposed column-base connections", Journal of Structural Engineering (ASCE) 142, No. 12, 2016

[8] Zareian F., Kanvinde A., "Effect of column-base flexibility on the seismic response and safety of steel moment-resisting frames", Earthquake Spectra 29, No. 4, pp. 1537-1559, 2013

[9] Kanvinde A.M., Grilli D.A., Zareian F., "Rotational stiffness of exposed column base connections: experiments and analytical models", Journal of Structural Engineering (ASCE) 138, No. 5, pp. 49-560, 2012

[10] Mackinven H., MacRae G.A., Pampanin S., Clifton G.C., Butterworth J, “Generation four steel moment frame joints", $8^{\text {th }}$ Pacific Conference on Earthquake Engineering, Singapore, 2007

[11] Chi H, Liu J., "Seismic behavior of post-tensioned column base for steel self-centering moment resisting frame", Journal of Constructional Steel Research 78, pp. 17-130, 2012

[12] Chou C-C., Chen J.H., "Analytical model validation and influence of column bases for seismic responses of steel post-tensioned self-centering MRF systems", Engineering Structures 33, No. 9, pp. 2628-2643, 2011

[13] Yamanishi T., Kasai K., Takamatsu T., Tamai H., "Innovative column-base details capable of tuning rigidity and strength for low to medium-rise steel structures", $15^{\text {th }}$ World Conference on Earthquake Engineering, Lisbon, Portugal, 2012

[14] MacRae G.A., Urmson C.R., Walpole W.R., Moss P., Hyde K., Clifton C., "Axial shortening of steel columns in buildings subjected to earthquakes", Bulletin of the New Zealand Society for Earthquake Engineering 42, No. 4, pp. 275-287, 2009

[15] Borzouie J,, MacRae G,A,, Chase J.G., Rodgers G.W., Clifton G.C., "Experimental studies on cyclic performance of column base strong axis - aligned asymmetric friction connections", Journal of Structural Engineering (ASCE) 142, No. 1, 2016

[16] ABAQUS/Standard and ABAQUS/Explicit - Version 6.13.1. "ABAQUS Theory Manual”, Dassault Systems, 2013

[17] Freddi F, Dimopoulos C.A., Karavasilis T.L., "Rocking damage-free steel column base with friction devices: design procedure and global seismic response of buildings", Proceedings of the $8^{\text {th }}$ European Conference on Steel and Composite Structures, Copenhagen, 2017

[18] Kamperidis V.C., Karavasilis T.L., Vasdravellis G., "Design and modeling of a novel damage-free steel column base", $8^{\text {th }}$ International Conference on Advances in Steel Structures. Lisbon, Portugal, July 2224, 2015

[19] Wolski M., Ricles J., Sause R., "Experimental Study of a Self-Centering Beam-Column Connection with Bottom Flange Friction Device", Journal of Structural Engineering (ASCE) 135, No. 5, pp. 479488, 2009

[20] Latour M., Piluso V., Rizzano G., "Free from damage beam-to-column joints: Testing and design of DST connections with friction pads", Engineering Structures 85, pp. 219-233, 2015

[21] Coelho A., Bijlaard F., Gresnigt N., da Silva L.S., "Experimental assessment of the behavior of bolted T-stub connections made up of welded plates", Journal of Constructional Steel Research 60, No. 2, pp. 269-311, 2004

[22] Haremza C., Santiago A., da Silva L.S., "Experimental behavior of heated composite steel-concrete joints subject to variable bending moments and axial forces", Engineering Structures 51, No. 150-161, 2013 